\title{
A Cognitive Semantics Approach to the Images and Implications of Female Devils in Journey to the West
}

\author{
Zhong Deng \\ Foreign Language School \\ Southwest Minzu University \\ Chengdu, China
}

\author{
Ziqi Lin \\ Foreign Language School \\ Southwest Minzu University \\ Chengdu, China
}

\begin{abstract}
Female devils in Journey to the West present themselves with a variety of images, thus attracting much attention with the aim to clarify their literary and cultural implications. This paper, by pointing out some inadequacy and inaccuracy of previous studies, intends reanalyze the images and implications of female devils in this novel from the perspective of cognitive semantics, believing that such an approach promises an improved and enriched interpretation.
\end{abstract}

Keywords-Journey to the West; female devils; conceptualization; implications

\section{INTRODUCTION}

Devil images, especially those of female devils, have been considered to be one of the most distinctive features of ancient Chinese ghost and demon novels. This is mainly because female devils (derived from the images of females culturally endorsed in ancient China) are recognized as less ferocious but more seducing than their male counterparts who are invariably depicted as physically strong and psychologically brutal (as is the case in western literary works). Such a perception renders a wide range of possibilities as to how the images of female devils can be varied and perplexing, making possible a variety of interpretations and associations in the wake. However, we have found that quite much of the existing research seems somewhat superficial, inadequate or even inaccurate. We believe these unsatisfying findings can be largely attributed to the inefficiency of the research perspectives or/and paradigms that have been adopted, that is, research patterns that have paid excessive attention to the plots, narrative line, ideology, religions, and other "broad frames". Although an academic pursuit under such frames is right and should be encouraged, we should be alarmed by the side-effects of doing so, an obvious one being that we are likely to flatten, minimize and standardize the roles of some participants in the story or plot, especially those who are easily regarded as agonists or "obstacles to the ultimate triumph". Devils, especially female devils, are a good example. It seems that as long as the readers and critics have labeled those devil

This paper is supported by the Fundamental Research Funds for Central Universities. Project Title: A Cognitive Linguistics Approach to Chinese Abbreviations and their Meaning-Forming Mechanism (No. 2015SZYQN127). It is also supported by SMU Students' Innovation and Entrepreneurship Program. Project Title: A Cognitive Approach to the Meanings of Devils in Journey to the West and their Translation in the English-speaking World (No. 201710656029). characters as devils, everything has been settled in that no one is likely to bother himself/herself to ponder whether THIS devil is different from THAT one, or whether male devils are different from female ones, or whether the images and behavior of a devil may affect the whole story and convey certain anticipated but untold significance. In a word, many scholars seem to have been intoxicated in picturing an extensive frame or scenario in which certain less important characters are presumably stereotyped or functionally identical, but they have failed to think in a reversed manner - the negatively "labeled" characters (such as female devils) are labeled this way simply because of a "safety concern" motivated by a conspiracy between the readers and critics who are not willing to rebuild their interpretations or comments, while the truth may be that the author did not mean such a "lowering" or "flattening" of these characters. In this sense, the exploration of this paper is justifiable and highly likely to be rewarding.

\section{PREVIOUS STUdIES}

The endeavors and findings of previous research, as briefly portrayed above, are centered to the following areas.

On the Plot: Both Yan (2007) and Yang (2010) claimed that female demons characterized with magic and multiple images serve as a constituent of the plot. In other words, they are defaulted by the plot without contributing anything more than what the plot has pre-set. To a large degree, this viewpoint "dwarfs" the potential significance of female devils.

On the narrative line: Duan (2014) believed that the conflict between the leading roles ( Bonze Tang and his three disciples) and the villains (devils) is the main line of the whole story. And it is the contradiction that enables the narration on. Therefore, the characters of devils, especially female ones can be righteously homogenous. This is, we believe, also an underestimate of the characters and roles of female devils because it continues to label these devils as part of a story.

On the ideology: Xi (2011) and Lin (2016) argued that the loftiness and greatness of the pilgrimage to the West for Buddhist Sutra are unlimitedly powerful and all devils are designed to help to highlight the heroic journey of piety and perseverance. Different from the research mentioned above, these studies are of higher cultural importance because they 
begin to look at the contributions of females devils not as needed by the story itself, but by the ideological considerations governing the story.

On the Religious background: some critics tend to look at female devils from the perspective of religions. Zang (2010) maintained that the creation of Journey to the West was greatly influenced by the combination of Confucianism, Buddhism and Taoism in the end of the Ming Dynasty. Thus, it was claimed that the female devils are religiously made and narrated. This perspective is meritorious because it tries to link female devils to the religious teachings familiar to Chinese people, resulting in collective sobriety and an easily accessible judgment on the part of the readers in terms of acquiring a distinction between what is Zheng (morally and religiously decent, i.e. Bonze Tang and his three disciples) and Xie (morally and religiously detrimental). But the problem is that, even if the female devils are given such an identity (Xie), they are still confined to a non-differentiated interpretation indistinguishable from any other Xie entities.

In a nutshell, such these research may have led to widespread misconceptions of not only the female devils but also of the novel itself, that is, the female demons could have been replaced by anyone or anything based on what is happening and being expected in the stories; therefore, female devils would have been deprived of a possibility of being interpreted as a specific entity as a literary and cultural symbol. In addition, given that there are scholars who regard these characters as a cultural symbol, they always interpret female demons with the traditional ideas of Confucianism, Buddhism and Taoism with Zheng and Xie as important considerations. Besides, although the analysis from a religious point of view is much related to traditional Chinese culture, it poses a new barrier to comprehending female demons to readers who are not steep into Chinese religions.

Consequently, we hold that only when we make an indepth exploration from other perspectives, can we achieve a better understanding of social, cultural and philosophical essence expressed by such female devils.

\section{A COGNITIVE SEMANTICS INTERPRETATION}

A cognitive interpretation is believed to be superior to the above-mentioned approaches for the following reasons. First, cognitive sciences (cognitive semantics in particular) that have made great progress since the 1980s have provided a brand-new perspective to look at language and literature, a perspective that differs from traditional paradigms in its adherence to the exploration into how humans' universal cognitive mechanisms interplay with and contribute to language and literature, as well as its insight into how meanings of language and literature can be worked out by integrating linguistic knowledge with world knowledge (Freeman 2007). Secondly, with the development of cognitive poetics (Tsur 1992; Stockwell 2002, 2009), scholars have matured their weapons for studies to a point where they can not only address traditionally important issues from a new perspective but also find out issues that previous research models failed to account for or unsatisfyingly dealt with, thus deepening the existing studies and promising encouraging findings, especially in terms of character analysis and the interpretation of characters' values (Xiong 2012).

More specifically, we intend to adhere to the theoretical core of cognitive semantics, i.e. conceptualization as the framework for this paper. This is because conceptualization, as the fundamental means for humans to make sense of the world, is central to the working out of meaning (Talmy 2000). In other words, meaning is the result of conceptualization (Langacker 2008). On the basis of such understanding, we may fairly agree that conceptualization also accounts for how the meaning of literature is constructed and understood (Shu 2016). This perception is very important because, unlike the traditional research on Journey to the West that focused mainly on the externalities that serve and shape the storytelling, the cognitive semantics approach gives priority to the internalities that make sense of meaning as it is, a more authentic meaning that arises from humans' universalities.

If we accept the applicability of conceptualization in our present study, we have to go further as to stress that meaning is encyclopaedic. This statement refers to that we should not understand the language meaning without considering the encyclopaedic knowledge related to it (Langacker 2008). From the perspective of the embodiment philosophy (a philosophical foundation of cognitive linguistics, see Turner 1996), encyclopaedic knowledge is the knowledge system constructed by the continuous interaction between human beings and the natural world and human societies. The knowledge system, including both the perceptual and rational cognition of a human body, alters and accumulates with the change of interactive space and time. What should be clarified here is that encyclopaedic knowledge is not concerned with the "externalities" mentioned above although it has to do with the world; instead, it is about the internal cognitive operations true of any individual if he or she wishes to gain the true meaning of language and literature, the very meaning that has to be grounded in perceivable human activities involved in the world but also has to be conceptualized (e.g. abstracted, schematized, etc.) as an insight or experience that differs from the tangible activities themselves.

Therefore, it makes sense that we try to unravel female devils from such a cognitive semantics perspective. In other words, we need focus on the conceptualization in the constructing the female devils, say, what cognitive mechanisms are at work in the writer's storytelling related to the female devils. Besides, considering that meaning is encyclopaedic, we have to be aware that the knowledge system formed by the interaction between people and the present world is extensive, diversified and encyclopaedic. What we aim to investigate is the conceptualization of $\mathrm{Wu}$ Cheng'en (author of this novel), namely conceptualization completed in the realm of traditional Chinese culture. And the variable factors of such conceptualization come from not only the universal cerebral factors, but also some traits of traditional Chinese culture which belongs to the category of encyclopaedic knowledge. Hence, only when we analyze the knowledge system to a nicety, can we find out a more precise interpretation of female devils which is in accordance with 
common cultural anticipation of Chinese people in the Ming Dynasty, and can we truly understand the main reason why the writer portrayed those female devils in his works.

\section{MAJOR FINDINGS}

Putting cognitive semantics into perspective, we aim to first all target some words, sentences, and poems in this novel that depict the images (including both appearances, utterances and behavior ) of female devils by categorizing them according to their origins (say, fleeing from heavenly institutions or self-cultivating through worldly practice). Then, we are to investigate the cognitive mechanisms involved in such depictions, in an attempt to figure out whether there are certain commonalities or inter-associations in terms of conceptualization and meaning-forming process. And finally, we may draw a safe conclusion on the literary and cultural implications of these female devils.

We have selected several female devils and list their respective appearances, utterances and behavior in the table given below. The criteria for the inclusion are mainly about whether the descriptions are relatively salient and representative or not so as to facilitate our analysis endeavor.

Our analysis begins with the concern whether such descriptions are approximate to the images of average women in ancient China. We find out that all descriptions here are strikingly or exceptionally distanced from what an ordinary woman was traditionally supposed to be like either in terms of their excessive seduction or from the perspective of their unwarranted intentions and behavior. Central to these descriptions are the language patterns as well as the ways of conceptualization associated with them that are seldom seen in other novels in ancient China.

1) The frequent use of nouns that are bodily seductive: face, complexion, feet, cheeks, lips, fingers, skin, waist... These nouns are directly associated with a woman's body, and such an unhidden relation is not a well-established paradigm in ancient Chinese literary norms (which are characterized by an indirect depiction usually incorporating euphemism and many other rhetorical devices). More importantly, such nouns are cognitively related to sexual implications by means of conceptual metaphor and metonymy, thus likely to activate readers' cognitive operations in this regard and to direct them to think of the female devils not simply as monsters destined to be defeated, but as a mental and moral characterization of seduction that makes the plot more complex and dramatic. Lastly, such nouns are often used in association with certain semantically enhancing adjectives such as those of colors (white, red...), shapes (willow, lotus...) and textures (jade-like, icesmooth...). Cognitively, as adjectives address nouns' encyclopedic relations with the world, such quoted examples highlight the degree of seduction presented by the female devils. Upon knowing these, we are justified in reevaluating the common perceptions of female devils by shifting the focus from their narrative contributions to their inherent complexity and cultural significance. In other words, the female devils were meant to profile a collective perception or assumption of how unorthodox females may become involved in serious undertakings of males as a source of distraction and seduction rather than simply as a foe to beat.

TABLE I. FEMALE DEVILS AND ThEIR DESCRIPTIONS

\begin{tabular}{|c|c|c|}
\hline $\begin{array}{c}\text { Female } \\
\text { Devils }\end{array}$ & Appearances & Utterances/Behavior \\
\hline $\begin{array}{l}\text { Corpse } \\
\text { Fiend }\end{array}$ & $\begin{array}{l}\text { Her brow was clear and her } \\
\text { eyes beautiful; her teeth } \\
\text { were white and her lips red. }\end{array}$ & $\begin{array}{l}\text { "Anyone who eats a } \\
\text { piece of his flesh will } \\
\text { live for ever" }\end{array}$ \\
\hline $\begin{array}{l}\text { Scorpion } \\
\text { Spirit }\end{array}$ & $\begin{array}{l}\text { Her fingers were as delicate } \\
\text { as spring onions. }\end{array}$ & $\begin{array}{l}\text { "Ask the Tang } \\
\text { emperor's brother in. } \\
\text { I'm going to make love } \\
\text { with him." }\end{array}$ \\
\hline $\begin{array}{l}\text { Iron Fan } \\
\text { Immortal }\end{array}$ & $\begin{array}{l}\text { Her face had the } \\
\text { complexion of a peach, her } \\
\text { body swayed like a willow } \\
\text { sapling. }\end{array}$ & $\begin{array}{l}\text { "Damn and blast you, } \\
\text { you careless fool." }\end{array}$ \\
\hline $\begin{array}{l}\text { Princess } \\
\text { Jade }\end{array}$ & $\begin{array}{l}\text { A ravishing beauty to } \\
\text { enchant a nation, walking } \\
\text { so slowly on her little lotus } \\
\text { feet. }\end{array}$ & $\begin{array}{l}\text { "She ought to know } \\
\text { better, the low bitch." }\end{array}$ \\
\hline $\begin{array}{l}\text { Apricot } \\
\text { Fairy }\end{array}$ & $\begin{array}{l}\text { This witch was as lovely as } \\
\text { the woman on Tiantai, no } \\
\text { less a beauty than the Zhou } \\
\text { king's concubine. }\end{array}$ & $\begin{array}{l}\text { "Noble guest, let's } \\
\text { make the most of this } \\
\text { wonderful night for } \\
\text { love. What are we } \\
\text { waiting for? Life is } \\
\text { short." }\end{array}$ \\
\hline $\begin{array}{l}\text { Spider } \\
\text { Spirit }\end{array}$ & $\begin{array}{l}\text { Red glows set off their } \\
\text { tender cheeks; Crimson } \\
\text { make-up was spread on } \\
\text { theirlips. }\end{array}$ & $\begin{array}{l}\text { At the really } \\
\text { magnificent footwork. } \\
\text { All the beauties shout } \\
\text { with admiration. }\end{array}$ \\
\hline $\begin{array}{l}\text { Gold-nosed } \\
\text { White- } \\
\text { haired } \\
\text { Mouse } \\
\text { Spirit }\end{array}$ & $\begin{array}{l}\text { Her feet were a pair of } \\
\text { curving golden lotuses; her } \\
\text { fingers were as delicate as } \\
\text { bamboo shoots in spring. }\end{array}$ & $\begin{array}{l}\text { "Little ones, bring } \\
\text { whatever there is, } \\
\text { vegetarian or not, and } \\
\text { burn paper as offering to } \\
\text { the deities." }\end{array}$ \\
\hline Jade Hare & $\begin{array}{l}\text { Graceful and charming, } \\
\text { Jadelike, and with ice- } \\
\text { smooth skin. }\end{array}$ & $\begin{array}{l}\text { "but because you've } \\
\text { wrecked my marriage I } \\
\text { hate you as much as if } \\
\text { you'd killed my mother } \\
\text { and father." }\end{array}$ \\
\hline
\end{tabular}

2) The bold use of verbs that are directly related to condemning, killing and sexual intercourse. Such a manner of using verbs is usually prohibited in ancient Chinese literary pieces for a strictly moral concern. Even in works that are centered on devils and monsters, such descriptions are rare for female ones. More noticeably, such verbs are not often used in SVO statements, but in imperative sentences and rhetorical questions as a conceptual bridge to link action to intention. These two traits of verbs help to profile other important characteristics of these female devils, that is, morally defiant and insufferably arrogant. Such an insight is of great significance because it goes against the traditionally programmed image of women featuring obedience and conformity (Even in terms of many other ghost-and-devil stories in ancient China, female devils often obey male ones or other superiors). Moreover, this understanding is expected to enrich our interpretation of female devils in that it provides some semantic and character clues that are not inherently specific to women but are eventually reinforced upon an ultimate realization that such clues can be made compatible with women.

Based on the cognitive analysis of the language patterns, and with the reference to the encyclopedic knowledge 
concerned with the language patterns, we may find out the implications of the female devils in this novel:

1) Firstly, female devils can be regarded as unorthodox and detrimental entities created in response to the collapse of traditional economic, political and cultural order of ancient China. In the middle and later period of Ming Dynasty, the long-standing feudal society of China was confronted with a host of challenges when capitalism began to sprout. The new economic pattern posed a profound impact on the feudal ethical system so that the social hierarchy along with the moral and behavioral codes attached to it began to alter. This helps to explain why female devils began to present themselves as sexually irresistible and morally despicable images in literary works. Besides, changes in ideology could be found then; take Li Zhi (the ideologist and litterateur of Ming Dynasty) for example, he put forward the idea "human desire is the principle of nature", which reflects the awakening of individual consciousness (Zhang 2004). Therefore, it seems not surprising that females' seduction (in the form of female devils) was boldly presented and elaborated in novels. In a word, the literary creation and accentuation of female devils can be interpreted as a mirror of the tremendous transformations and a means to express the anxiety of the learned (those who upheld the feudal values) about the emergence of seducing, irresistible and morally unconventional women (who had been quenched and condemned before) because they were uncertain of what might ensue, nor were they sure whether what might happen meant blessing or curse. The best effort they could have made was to implant such anxiety and uncertainty into a heroic story in which anything that annoyed and agitated them was doomed to failure.

2) Secondly, female devils can be interpreted as the literary projection of values and psychological mechanism of males in feudal society. Although the traditional feudal system had not collapsed yet, the circumstances already panicked males who had been unquestionably dominant. Then, what if it collapsed? In the novel, those female devils are free from the hierarchical order and do whatever they like without any obedience to and respect for male superiors, which seems to be abnormal, capricious and resentful in males' eyes. However, a closer look at the utterances and behavior of such female devils reveals that whatever the females are doing and saying is nothing but a replicate of what a man is supposed to say and do under certain circumstances. In other words, if the females are substituted by males, such utterances and behavior may not seem to be defiant and arrogant. Thus we may say these female images are endowed with male traits. There are two important implications:

To begin with, female devils are created to represent some deeply-hidden psychological traits of males, especially those traits that are not endorsed by the mainstream values but stubbornly inerasable in the mind of males such as the desire for sex, greed for wealth and impulse of condemning and killing people they resent. In this way, females become the "spokesperson" of males' vicious intentions.
In addition, female devils are essentially "devilized females". By "devilized", we mean it was males' deliberate literary creation and modification that contributed to the devilization (alienation) of females. The traits which inherently belong to a vicious male is now transferred to a female, and just because of the gender difference, the target female is given more negative implications as she has been labeled as seductive and morally degraded beforehand. This way, the female was further devilized, and the best endeavor males could have done was to project the devil images into literary works in which female devils were to be defeated along with the wickedness which had been originated from males themselves.

\section{CONCLUSION}

In summary, we believe that the images and implications of female devils in the novel Journey to the West can be well addressed from a cognitive semantics perspective. We find out that the images of female devils are of generally two categories: sexually seductive and morally defiant. We associate these findings with a cognitive interpretation and conclude that such images represent 1) the anxiety and uncertainty of the mainstream culture and 2) the deliberate transference of males' wickedness to females. We believe we may have reached a relatively more satisfactory conclusion compared with those of previous studies and we sincerely hope there can be other studies to further our understanding.

\section{REFERENCES}

[1] Freeman. M. The Fall of the Wall BetweenLiterary Studies and Linguistics: Cognitive Poetics. In Gitte Kristiansen, Michel Achard, René Dirven, and Francisco Ruiz de Mendoza, eds. Applications of Cognitive Linguistics: Foundations and Fields of Application, 403428. Berlin: Mouton de Gruyter, 2007.

[2] Langacker, R.W. Cognitive Grammar: A Basic Introduction. [M].Oxford: Oxford University Press, 2008.

[3] Stockwell. P. Cognitive Poetics: An Introduction. [M].London: Routledge, 2002.

[4] Stockwell. P. Texture: A Cognitive Aesthetics of Reading. Edinburgh: Edinburgh University Press, 2009.

[5] Talmy, L. Toward a Cognitive Semantics, Vol II: Typology and Process in Concept Structuring. [M].Cambridge/Massachusetts: The MIT Press, 2000.

[6] Tsur. R. Toward a Theory of Cognitive Poetics. Amsterdam: NorthHolland, 1992.

[7] Turner, M. The Literary Mind: The Origins of Language and Thought. [M].Oxford: Oxford University Press, 1996.

[8] Duan Xinjiao, Cultural Analysis on the Images of Female Devils in "Journey to the West". [J]. Journal of the Party School of CPC Zhengzhou Municipal Committee, 2014 (05).

[9] Lin Mei,Sadness over Misfortunes and Anger over DiscouragementThe Analysis of Banshees Image and its Thought Value in the "Journey to the West" [J]. Journal of Hubei Correspondence University, 2016 (20).

[10] Shu Dingfang, "jingjie" and "Conceptualization"- Poetic Theory of Wang Guowei and Conceptual Theory in Cognitive Linguistics. [J]. Foreign Language Education, 2016 (7) :1-5.

[11] Wu Cheng'en and Jenner.W.J.F (trans), Journey to the West (Chinese-English). [M]. Beijing: Foreign Language Press, 2003.

[12] Xi Guangwei, Demons in "Journey to the West". [M]. Beijing: Knowledge Press, 2011. 
[13] Xiong Muqing, Analytical Technique of Cognitive Poetics: A Case Study of The Eagle. [J]. Foreign Language Teaching and Research, 2012 (5):448-459

[14] Yan Xiaoxing, Towards the Shaping of Female Demons in Classical Chinese Literature from "Journey to the West". [J]. Journal of Zhangzhou Technical Institute, 2007 (04).

[15] Yang Renli, Being Heartless or Passionate - Writer's State of Mind When Creating the Image of Succubae in the Novel Journey to the West. [J]. Journal of the Qiannan Normal College for Nationalities, 2010 (05).

[16] Zang Huiyuan, Obedience to Feudal Ethical Codes, Perfect and Rebellion-Interpretation of Images of Females in "Journey to the West". [J]. Journal of Henan Normal University, 2010 (06).

[17] Zhang Hongxia, Sentence to "Default" of Women - On Shaping of Images of Females in "Journey to the West". [J]. The Research On Ming \&Qing Dynasties Novels,2004 (02). 